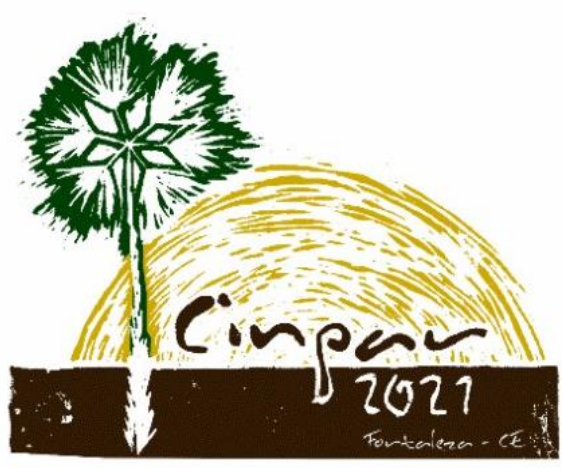

XVII Congresso Internacional sobre Patologia e Reabilitação das Construções

XVII Congreso Internacional sobre Patología y Rehabilitación de las Construcciones

XVII International Conference on Pathology and Constructions Rehabilitation

FORTALEZA (Brasil), 3 a 5 de junho de 2021

https://doi.org/10.4322/CINPAR.2021.025

\title{
Inspeções em obras de artes especiais a partir da utilização de drone: Estudo de caso da Ponte Pedra do Cavalo-BA
}

\section{Bridge inspections using a drone: Case study of Ponte Pedra do Cavalo-BA}

\author{
Thomas GONÇALVES ${ }^{1}$, Vanessa GONÇALVES ${ }^{2}$, Bruna ROSA ${ }^{3}$, Willian PEREIRA ${ }^{4}$, Alexandra PASSUELLO ${ }^{5}$ \\ ${ }^{1}$ Universidade Federal do Recôncavo da Bahia, Cruz das Almas-BA, Brasil, thomassfgoncalves@gmail.com \\ ${ }^{2}$ Universidade Federal do Recôncavo da Bahia, Cruz das Almas-BA, Brasil, vanessaedfgg@gmail.com \\ ${ }^{3}$ Universidade Federal do Recôncavo da Bahia, Cruz das Almas-BA, Brasil, brunarosa94@hotmail.com \\ ${ }^{4}$ FACTIVA, Valença-BA, Brasil, w.pereira@hotmail.com \\ ${ }^{5}$ Universidade Federal do Recôncavo da Bahia, Cruz das Almas-BA, Brasil, passuello@ufrb.edu.br
}

\begin{abstract}
Resumo: Os altos custos de investimento envolvidos no programa de manutenção das obras de artes especiais (OAE's) se tornam um dos principais motivos para a frequente falta de inspeções neste tipo de estruturas. Diante disso, a inserção dos drones no inspecionamento dessas construções tem se mostrado atrativa, visto que prometem dar agilidade na obtenção de informações e reduzir os custos operacionais do serviço. Esta pesquisa possui como objetivo avaliar as potencialidades e limitações do uso de drones como ferramenta de inspeção em pontes, levando em consideração os procedimentos tradicionalmente adotados e normalizados pelo Departamento Nacional de Infraestrutura de Transportes (DNIT). A pesquisa teve como objeto de estudo a Ponte Pedra do Cavalo, localizada no Recôncavo da Bahia e sob jurisdição do DNIT. A análise da estrutura foi delimitada nos elementos de maior criticidade: juntas de dilatação, aparelhos de apoio, cabeças de pilares e sistema de drenagem. O drone utilizado foi o DJI modelo Phantom 4 Advanced, com sensor óptico embarcado. Os resultados apontaram que o drone agilizou a coleta de informações, permitindo a visualização de grande parte dos elementos estruturais e potencial para ampliar a frequência da realização das inspeções executadas pelo DNIT. Entretanto, existiram limitações no acesso de algumas regiões da estrutura devido a condicionantes de naturezas distintas, sendo algumas de possíveis soluções a partir da troca do equipamento e método de trabalho. Mediante as imagens do drone foi possível identificar manifestações patológicas, anomalias construtivas e falhas que comprometem a vida útil da estrutura. As imagens do drone também permitiram identificar pontos mais sensíveis para complementação da análise a partir de uma inspeção visual direta.
\end{abstract}

Palavras-chave: Obras de Artes Especiais, Inspeção, Drones, Manifestações Patológicas.

Abstract: The high investment costs involved in the maintenance program of the bridges become one of the main reasons for the frequency of inspections in this type of structures. Therefore, the insertion of drones in the inspection of these constructions has proven to be attractive, since they promise to provide agility in obtaining information and reduce the operational costs of the service. This research has the objective of evaluating the potentialities and limitations of the use of drones as an inspection tool in bridges, taking into consideration the procedures traditionally adopted and normalized by the National Department of Transportation Infrastructure (DNIT). The research had as object of study the Pedra do Cavalo Bridge, located in Recôncavo da Bahia and under jurisdiction of DNIT. The structure analysis was delimited in the most critical elements: expansion joints, support devices, pillar heads and drainage system. The drone used was the DJI model Phantom 4 Advanced, with embedded optical sensor. The results showed that the drone speeded up the collection of information, allowing the visualization of a large part of the structural elements and potential to increase the frequency of inspections performed by DNIT. However, there were limitations in the access of some regions of the structure due to conditions of different natures, being some of possible 
solutions from the change of equipment and working method. Through the images of the drone it was possible to identify pathological manifestations, constructive anomalies and failures that compromise the useful life of the structure. The images of the drone also allowed to identify more sensitive points to complement the analysis from a direct visual inspection.

Keywords: Bridges, Inspections, Drone, Pathological Manifestations.

\section{Introdução}

Segundo Timerman apud Santos (2017) estima-se que no Brasil existem cerca de 120 mil pontes e viadutos, onde 111 mil destas estruturas são gerenciadas por órgãos estatais das três esferas de governo, enquanto somente 9 mil são de responsabilidade de concessionárias. Levando em consideração essa estimativa, os dados relacionados ao cadastramento de todas essas estruturas, assim como o conhecimento sobre o seu real estado de conservação ainda é um desafio a ser vencido. De acordo com o relatório de auditoria operacional do Tribunal de Contas da União, realizado em fevereiro de 2012, o Departamento Nacional de Infraestrutura de Transportes (DNIT), responsável pelo gerenciamento das estradas federais, apresentava dificuldades em seguir os critérios da Norma DNIT 010/2004-PRO, em relação a abrangência e peridiocidade das inspeções rotineiras, não conseguindo realizá-las na sua totalidade dentro do intervalo máximo normativo de 2 anos. Inclusive, o mesmo documento indica que as últimas inspeções realizadas de forma sistemática teriam acontecido entre os anos de 2002 e 2004 e das 4.469 obras que estão sob responsabilidade do DNIT, 3.351 encontram-se em mau estado de conservação.

Diante do exposto, a problemática atual em relação ao estado de conservação das pontes gerenciadas pelo poder público gira em torno do desconhecimento da real situação devido a frequência exígua das inspeções requeridas. A dificuldade de acesso em todos os pontos da estrutura requer, muitas vezes, a mobilização de equipamentos e interdição de vias, acarretando em custos elevados, e em certos casos, gerando até mesmo risco a segurança do inspetor (RAUBER, et al. 2018).

Por outro lado, o mercado atual tem oferecido novas tecnologias que prometem facilitar o gerenciamento do acompanhamento do estado de conservação de estruturas, em especial as obras de arte especiais (OAE's). Uma das alternativas é a utilização de drones, um tipo de veículo aéreo não tripulado (VANT) mais compacto, porém com capacidade de embarcar uma série de sensores para captação de imagens de diferentes naturezas. Estes equipamentos podem chegar rapidamente a pontos de difícil acesso, sem que haja a necessidade de aproximação do operador ou instalação de andaimes e plataformas, tornando a inspeção mais rápida, segura e barata.

Considerando que o drone pode ser uma ferramenta facilitadora nas atividades de inspeções, avaliar a eficiência destas aeronaves no uso de inspeções de estruturas pode permitir avanços nos procedimentos atualmente adotados. A presente pesquisa busca avaliar as potencialidades e limitações do uso de drones como ferramenta de inspeção em pontes, levando em consideração os procedimentos tradicionalmente adotados e normalizados pelo DNIT. O objeto de estudo foi a Ponte da Pedra do Cavalo, localizada sobre o Rio Paraguaçu, no Km 200,49 da Rodovia Mário Covas (BR 101), Recôncavo da Bahia.

\section{Referencial Teórico}

\subsection{Gerenciamento e monitoramento de OAE em rodovias federais}

O gerenciamento de OAE em rodovias federais está sob a jurisdição do Departamento Nacional de Infraestrutura de Transportes (DNIT), que adota a norma DNIT 010/2004 - PRO para gerenciamento e monitoramento destas estruturas. $\mathrm{O}$ acompanhamento das pontes e vidadutos sob responsabilidade do DNIT é realizado a partir do Sistema de Gerenciamento de Obras de Arte Especiais (SGO), cuja data base possui todas as informações coletadas ao longo da vida útil da obra, permitindo assim um planejamento sobre as manutenções necessárias requerida pela norma, para que assim seja garantido a eficácia desse Sistema de Gestão. 
De acordo com a norma DNIT, as inspeções são classificadas em cinco tipos, diferenciando-se pelos objetivos previstos para cada uma delas, são elas: Inspeção cadastral, sendo essa a primeira inspeção que a estrutura receberá logo após a sua construção e que proverá as informações que serão cadastramentas no SGO, ou então, quando é realizada alguma mudança significativa do projeto, tal como alargamentos e outras mudanças na geometria; Inspeção rotineira, realizada com uma frequência de no máximo dois anos; Inspeção especial, realizada com uma frequência de cinco anos; Inspeção extraordinária, realizada quando ocorre um grave acidente na obra; Inpeção intermediária, proposta para monitorar uma deficiência suspeitada ou já detectada.

Os requisitos mínimos para realizar, com segurança, uma inspeção confiável e completa são o planejamento e a programação adequada, estas duas atividades deverão abordar os seguintes aspectos: motivo e tipo de inspeção, dimensionamento da equipe, equipamentos e ferramentas, projetos e relatórios anteriores e ainda o período do ano mais favorável a este tipo de investigação. Todos os aspectos citados anteriormente são primordiais a execução de uma boa inspeções, todavia, a escolha de equipamentos e ferramentas adequadas poderá influenciar totalmente na dinâmica da inspeção e numa maior abrangência quanto ao número de pontes inspecionadas. Em relação aos elementos da OAE que devem ser inspecionado a norma do DNIT apresenta cada um deles com suas respectivas observações do que pode ser analisado durante a inspeção.

\subsection{Uso de drones em inspeções de estruturas}

Muitas das pontes existentes no Brasil não dispõem de plataformas de inspeções, tornando necessário que durante essa atividade seja utilizado meios de acesso que facilitem a proximidade e visualização do Inspetor da região a ser inspecionada. Segundo Giovannetti (2014), os dois principais meios de alcançar regiões de difícil acesso de uma ponte são por meio de equipamentos de acesso e veículos de acesso. Como equipamento de acesso podem ser citados o mais comuns, como escadas, andaimes apoiados ou suspensos, plataformas apoiadas em torres tubulares e barcos ou balsas. Os veículos especiais de acesso oferecem um rápido e seguro acesso a região que deve ser analisada, todavia, seu aluguel possui um alto custo. Exemplos desses veículos são os caminhões do tipo Munck e os "snoopers", ambos possuem braços articulados e cestas, entre outras características que os diferenciam.

Um equipamento que tem apresentado potencial na facilitação dos serviços de inspeções visuais são os veículos aéreos não-tripulados (VANT's) que possuem carga útil adequada no embarque de sensores para coleta de informações (DCEA, 2010). Atualmente existem vários modelos de VANT's, de diferentes características e tamanhos. Os VANT's do tipo multirrotor, conhecidos também como drones, são os mais indicados para inspeções devido a sua capacidade de mover-se em todas as direções num espaço limitado e pairar no ar sem perder a estabilidade (RAUBER, et al. 2018). Os drones podem voar ao redor da estrutura em estudo, possibilitando a aproximação para coleta de imagens e vídeos de alta resolução, dando condições ao inspetor de visualizar os elementos estruturais e analisar a sua integridade de forma ágil e segura.

Considerando que os VANT's são equipamentos que utilizam o espaço aéreo, sua utilização é regulamentada pelo Estado. A legislação brasileira acerca dos procedimentos para acesso a esse espaço é de competência do Ministério da Defesa, no âmbito do Sistema de Controle do Espaço Aéreo Brasileiro (SISCEAB) e através do Departamento de Controle do Espaço Aéreo (DECEA). Compete à Agência Nacional de Aviação Civil (ANAC) administrar o Registro Aeronáutico Brasileiro (RAB), assim como emitir Certificados de Matrícula (C.M.) e de Aeronavegabilidade (C.A.) de aeronaves civis sujeitas à legislação brasileira. Para a execução do voo se torna necessário uma solicitação ao DECEA, informando a intensão do voo, caso comercial ou recreativo, localização e a altura. A autorização de uso do espaço aéro deve ser realizada no Sistema de Autorização para Acesso ao Espaço Aéreo por Aeronaves Não Tripuladas - SARPAS (DECEA, 2010).

\section{Metodologia}

\subsection{Caracterização do objeto de estudo}

A Ponte Pedra do Cavalo (Figura 1), foi construída na década de 1980 e está localizada no Km 200.49 da BR 101- Rodovia Governador Mário Covas, situada no Recôncavo baiano. A OAE possui largura total de 12.2 metros com disposição de duas faixas de rolamento, cada uma com $3.5 \mathrm{~m}$, acostamentos em ambas as faixas, 
com largura de $2.6 \mathrm{~m}$ cada. A estrutura tem um comprimento de $498 \mathrm{~m}$, dividida em 11 vãos distribuído da seguinte forma: um vão de $39.2 \mathrm{~m}$, seis vãos de $40.2 \mathrm{~m}$, dois de $60.10 \mathrm{~m}$, um de 37.2 e outro de $42.2 \mathrm{~m}$.

Em termos de estrutura a ponte possui um sistema misto de apoios sendo constituída por elementos de concreto armado e protendido. No sistema estão dispostos 10 pilares do tipo pilar-parede que servem de apoio para as vigas protendidas, responsáveis por distribuir os esforços gerados pela laje do tipo nervurada com longarinas transversais. Além disso, a obra de arte é composta por 7 juntas de dilatação, distribuídas ao longo do comprimento da ponte. A Figura 2 mostra a disposição dos pilares e dos vãos através de um croqui representativo. É importante mencionar que a ponte estudada não possui plataformas de inspeção.

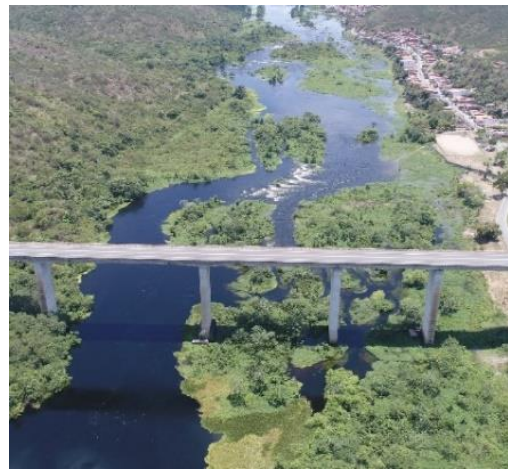

Figura 1- Vista superior da ponte

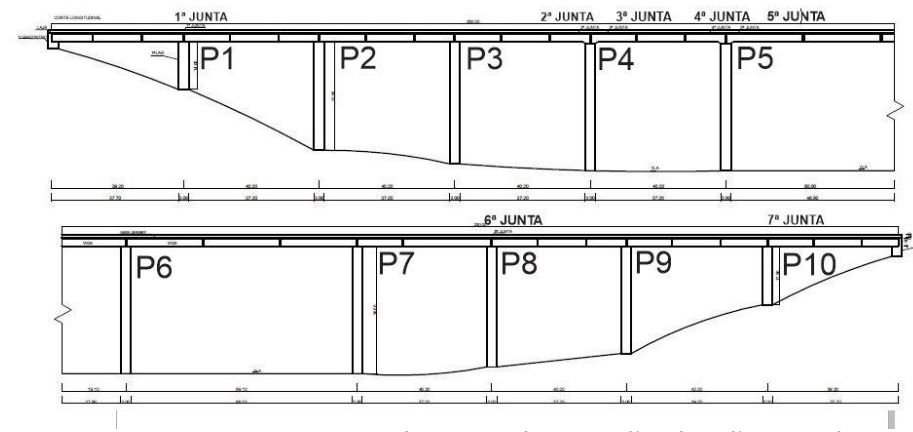

Figura 2- Esquema estrutural com a disposição de vãos e pilares

\subsection{Método da pesquisa}

O método de inspeção adotado para esta pesquisa adotou os procedimentos requeridos pela norma DNIT 010/2004 - PRO, considerando tanto uma inspeção visual direta quanto uma inspeção realizada a partir das imagens obtidas por um drone. 0 equipamento utilizado foi um DJI Phantom 4 Advanced, multirotor 4 eixos, com sensor RGB (SONY EXMOR 1" CMOS) embarcado para registro das imagens, que possibilita a aquisição de vídeos em resolução $4 \mathrm{~K}$ a 60 frames por segundo e imagens com resolução de 20 megapixels. Um total de quatro bateriais foi utilizado na coleta de imagens desse trabalho.

Antes da realização da inspeção foi realizada uma visita preliminar para que os inspetores pudessem se ambientar com o local da obra, verificando os locais de acesso para a equipe, os pontos de apoio para operador do drone, as condições de segurança de deslocamento, bem como as áreas adjacentes. Essa primeira visita também foi importante para dar base ao planejamento da inspeção, de forma a otimizar o trabalho e a coleta de imagens pelo drone. A inspeção ocorreu em um único turno e foi realizada por uma equipe de 4 pessoas, sendo 3 engenheiros e 1 auxiliar. Metade da equipe ficou responsável pela coleta de imagens com o drone e metade responsável pela inspeção visual direta do tabuleiro superior da ponte. Importante ressaltar que, o trânsito não foi bloqueado durante as atividades, porém foi gerido pela própria Polícia Federal que esteve presente durante os trabalhos.

A inspeção foi realizada em dois momentos distintos. No primeiro momento foram registrados vídeos e imagens referentes aos pilares, parte inferior (tabuleiro, cabeça dos pilares e aparelhos de apoio) e laterais da ponte. Iniciou-se pela encontro esquerdo, próximo aos pilares P1, P2, P3, P4 e P5, cuja distância permitia o posicionamento do operador de forma a ter acesso visual do drone para evitar possíveis colisões. Esse procedimento foi requerido, pois o equipamento utilizado não era dotado de sensores suficientes para a realização de um voo manual sem riscos de queda. A aquisição das informações durou aproximadamente $1 \mathrm{~h}$. Em um segundo momento, foram capturadas imagens e vídeos do tabuleiro superior a partir de um voo automático, já que não existiam obstáculos que pudessem comprometer o equipamento. Essa fase da inspeção durou cerca de 15 minutos. A solicitação do voo foi realizada no DECEA através do SARPA, obtendo autorização de número \#671B82.

A inspeção visual direta foi realizada pelos inspetores utilizando uma câmera de celular para registro fotográfico. Considerando que as condições para a inspeção não foram as mais favoráveis para a circulação da equipe (presença de vegetação, rio com vazão intermediária), as informações foram complementadas por relatórios de inspeções provenientes do DNIT, realizados nos anos de 2019, 2018 e 2013. 
A análise das imagens obtidas pelas duas formas de inspeção visual (direta e com o drone) buscou entender as potencialidades e limitações a respeito da visualização dos elementos da estrutura por meio do drone e como esse equipamento poderia contribuir com o método tradicional utilizado pelo DNIT.

\section{Resultados e Discussões}

A partir dos dados coletados por meio da metodologia da pesquisa, foi elaborado o Quadro 1, que apresenta a capacidade de visualização dos elementos da estrutura da ponte a partir de dois métodos distintos, que é o método de inspeção visual direta, normatizado pelo DNIT, e o método complementar utilizando o drone.

Quadro 1 - Capacidade de visualização dos elementos da estrutura pelos distintos métodos

\begin{tabular}{|c|c|c|c|c|c|}
\hline & $\begin{array}{c}\text { Elementos da } \\
\text { Estrutura }\end{array}$ & $\begin{array}{c}\text { Visualização } \\
\text { total }\end{array}$ & $\begin{array}{c}\text { Visualização } \\
\text { Parcial }\end{array}$ & $\begin{array}{c}\text { Visualização } \\
\text { Limitada }\end{array}$ & Motivo da Limitação Visual \\
\hline \multirow{7}{*}{$\begin{array}{l}\text { Inspeção } \\
\text { visual direta }\end{array}$} & Encontros & $x$ & & & - \\
\hline & $\begin{array}{l}\text { Pilares P1, P2, } \\
\text { P3, P4 e P5 }\end{array}$ & & $x$ & & $\begin{array}{c}\text { Aproximação do Inspetor do } \\
\text { elemento }\end{array}$ \\
\hline & $\begin{array}{l}\text { Pilares P6, P7, } \\
\text { P8, P9, P10 }\end{array}$ & & $x$ & & $\begin{array}{c}\text { Aproximação do Inspetor do } \\
\text { elemento }\end{array}$ \\
\hline & $\begin{array}{l}\text { Aparelhos de } \\
\text { Apoio }\end{array}$ & & & $x$ & $\begin{array}{c}\text { Alcance do Inspetor sem uso de } \\
\text { recurso externos }\end{array}$ \\
\hline & $\begin{array}{l}\text { Juntas de } \\
\text { Dilatação }\end{array}$ & $x$ & & & - \\
\hline & Drenos & $x$ & & & - \\
\hline & Vigas Laterais & & $x$ & & $\begin{array}{c}\text { Aproximação do Inspetor do } \\
\text { elemento }\end{array}$ \\
\hline \multirow{7}{*}{$\begin{array}{l}\text { Inspeção com } \\
\text { o drone }\end{array}$} & Encontros & & & $x$ & Vegetação Densa \\
\hline & $\begin{array}{l}\text { Pilares P1, P2, } \\
\text { P3, P4 e P5 }\end{array}$ & $x$ & & & - \\
\hline & $\begin{array}{l}\text { Pilares P6, P7, } \\
\text { P8, P9, P10 }\end{array}$ & & & $x$ & $\begin{array}{l}\text { Visualiação do operador em } \\
\text { relação ao drone e não acesso a } \\
\text { área adjacente em função da } \\
\text { presença de vegetação e curso } \\
\text { hídrico }\end{array}$ \\
\hline & $\begin{array}{l}\text { Aparelhos de } \\
\text { Apoio }\end{array}$ & & & & $\begin{array}{l}\text { Alcance do drone e falta de } \\
\text { iluminação e falha no GPS }\end{array}$ \\
\hline & $\begin{array}{l}\text { Juntas de } \\
\text { Dilatação }\end{array}$ & & $x$ & & $\begin{array}{l}\text { Aproximação do drone em relação } \\
\text { ao elemento }\end{array}$ \\
\hline & Drenos & & $x$ & & $\begin{array}{l}\text { Aproximação do drone em relação } \\
\text { ao elemento }\end{array}$ \\
\hline & Vigas Laterais & $x$ & & & - \\
\hline
\end{tabular}

O drone utilizado não apresentou potencialidade para visualização dos encontros da estrutura, embora o equipamento demonstre capacidade de desvio de obstáculos, a vegetação densa impossibilitou a aproximação do equipamento, devido ao risco de queda. A Figura 3 mostra o pilar P1 que está à frente do elemento que pretendia ser inspecionado pelo VANT. Na imagem é posssível observar a vegetação que limita a visualização do encontro. O relatório de inspeção rotineira do DNIT no ano de 2019 apresenta na sua inspeção visual direta registro fotográfico de um encontro (Figura 4), mas nela percebe-se que houve a necessidade da descida do inspetor no morro para coleta da fotografia e muito provavelmente, quando o órgão fez a inspeção, foi realizado uma limpeza prévia da área, para viabilizar a visualização do elemento.

A cabeça dos pilares $\mathrm{P} 1$ a P5 foram abordadas de maneira eficiente pelo drone (Figura 5), porém é importante ressaltar a dificuldade de aproximação na face esquerda do pilar P1 visualizado na Figura 3, isto devido a presença de vegetação densa próximo desse elemento, que atrelada a uma maior vazão no curso hídrico acarretou na falta de possibilidade de movimento do operador para que aumentasse a visibilidade em relação a aeronave, não sendo possível captar as imagens referentes aos pilares P6, P7, P8, P9 e P10. Possivelmente, a utilização de embarcações poderia ter permitido a aproximação do operador do drone, possibilitando a captação das imagens. É importante evidenciar que durante a inspeção o rio estava mais cheio e em alguns momentos facilitava a circulação na base da ponte. No relatório do DNIT foi coletado 
imagens de todos os pilares, porém vale salientar que as fotografias registradas possuem uma baixa qualidade de visualização, visto que foram capturadas muito distante do elemento de estudo. Além disso, algumas imagens foram registradas atrás de arbusto, local que não favorecia a visualização do pilar P2. As Figuras 5 e 6 apresentam imagens do pilar P2, uma obtida com o drone e outra obtida por inspeção visual direta com máquina fotográfica, respectivamente. Devido a impossibilidade de obter contato visual completo em todos os pilares da ponte, seja com a inspeção direta ou mesmo com o drone, a visualização foi classificada como parcial em ambos métodos, entretanto, foi mais abrangente quando o drone foi utilizado.

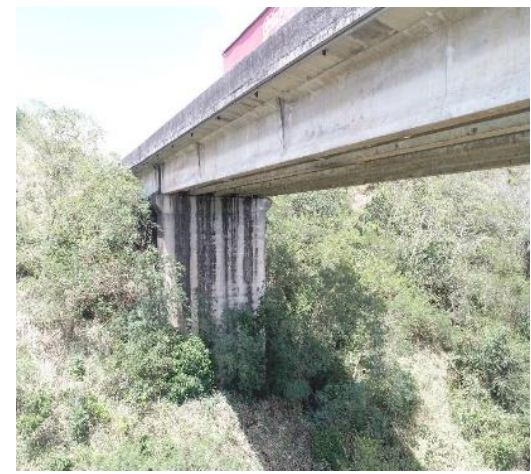

Figura 3- Imagem do drone

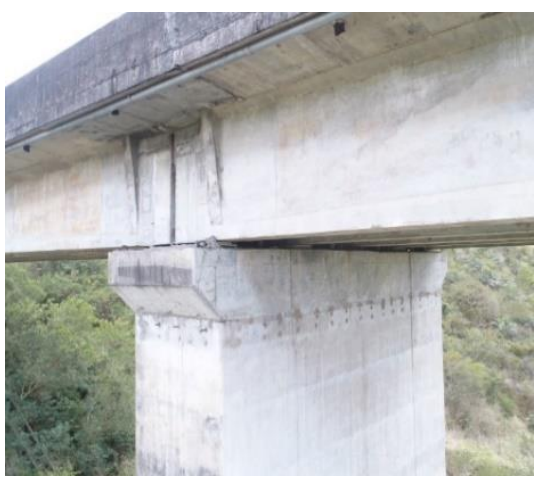

Figura 5- Imagem do drone

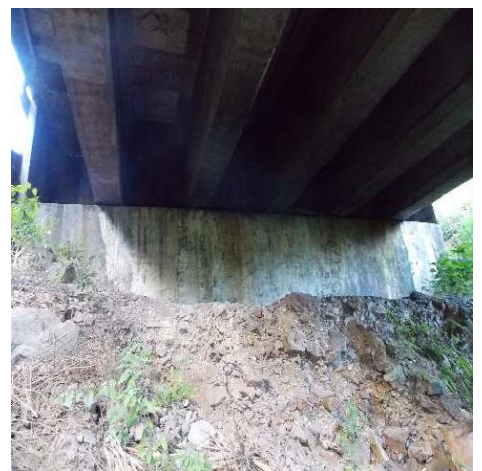

Figura 4- Imagem do relatório DNIT

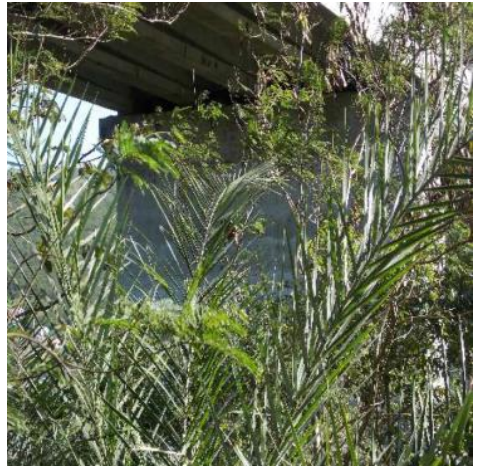

Figura 6- Imagem do relatório DNIT

Os aparelhos de apoio foram os elementos que apresentaram maiores dificuldade na obtenção das imagens pelo drone, devido ao sistema estrutural adotado no projeto, bem como o tipo e dimensões desses aparelhos. A falta de luminosidade nesta posição da estrutura também foi um fator que contribuiu negativamente na aquisição das imagens. No entanto, possivelmente a utilização de outros equipamentos existentes no mercado, com menor dimensão e com sensores mais sensíveis a luminosidade, poderia ter resolvido este problema. Além disso, foi identificado uma perda de sinal do GPS no momento em que o veículo aéreo circulou na parte inferior do tabuleiro. Essa situação impossibilitou o adequado controle do equipamento, perdendo a garantia de aquisição de imagens que fornecessem condições de visualização do local. Nos documentos do DNIT também não constam nenhuma inspeção desses elementos, isso pode ser consequência da não utilização por parte da equipe de dispositivos de acesso como veículos especiais. Dependendo do tipo de aparelho de apoio adotado no projeto, a sua visualização sempre será limitada quando não forem utilizados equipamentos ou veículos especiais que levem o inspetor até essa área. Considerando os custos e riscos do uso de dispositivos de acesso, talvez a aquisição de um drone com tecnologia mais atual posssa permitir uma melhor visualização.

As imagens coletadas das juntas de dilatação e dos drenos através do drone apresentaram resultados parciais, visto que a distancia do aparelho ao tabuleiro precisava ser grande, pois o tráfego não foi interrompido. Através das imagens do VANT era possível ver solo carreado, lixo, vegetação, todavia, não foi possível analisar a integridade dos materiais das juntas, muito menos avaliar corretamente a obstrução dos drenos somente com as imagens do drone. Para entender o real estado de conservação desses elementos foi necessário a inspeção visual direta pela equipe. Ainda assim, as juntas e drenos são elementos de fácil acesso, podendo ser observadas por cima do tabuleiro.

A partir de uma caminhada sobre o pavimento foi possível perceber que dos 76 drenos previsto no projeto, somente 9 estavam completamente desobstruidos. A obstrução devido a grande presença de solo carreado, 
lixo e raízes de vegetação (Figura 7) conduz a água pluvial pela junta de dilação e mantém permanentemente úmida a cabeça do pilar. Em relação as juntas foi indentificado um total de 7 ao longo da ponte com espaçamentos variáveis, mas de acordo o documento da inspeção realizada em 2013 pelo DNIT existem apenas 6, dado que não confere com o que foi observado em campo. Além disso, foi confirmado também a presença de materiais asfálticos na superfice das juntas de dilatação, o que impossibilita a movimentação natural das juntas, fazendo com que naquela região apareçam trincas nos pavimentos (Figura 8).

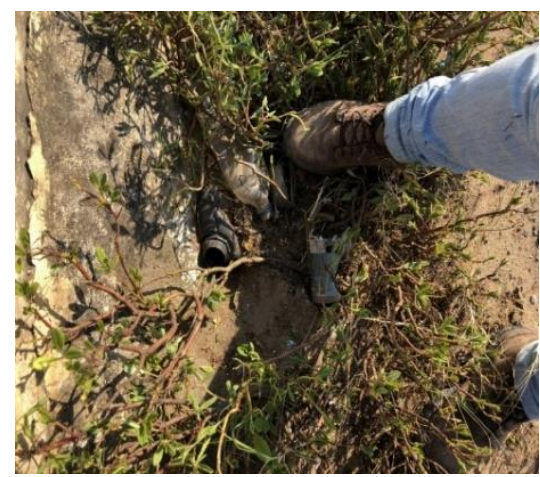

Figura 7 - Imagem do drone

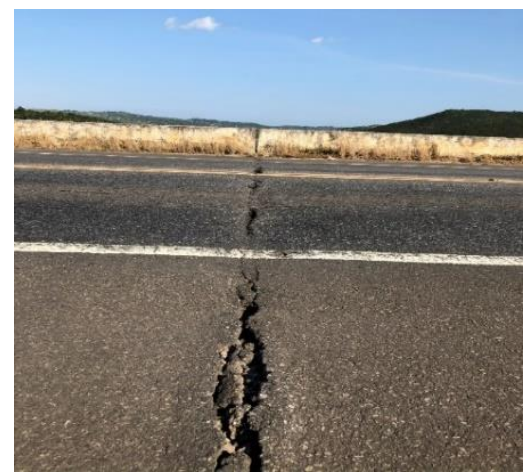

Figura 8 - Material deteriorado na superfície da junta

As imagens das vigas laterais foram facilmente registrada pelo drone (Figura 9). No relatório do DNIT também constam as fotografias das vigas laterais (Figura 10), no entanto, devido essas imagens serem registradas distante do elemento estudado, houve uma significativa queda na qualidade da resolução das fotos.

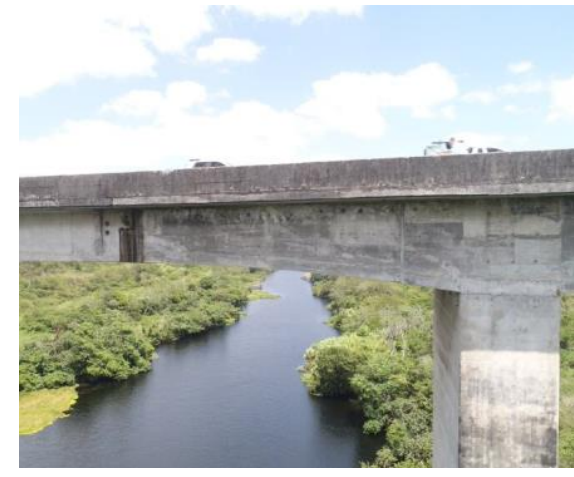

Figura 9- Imagem do drone)

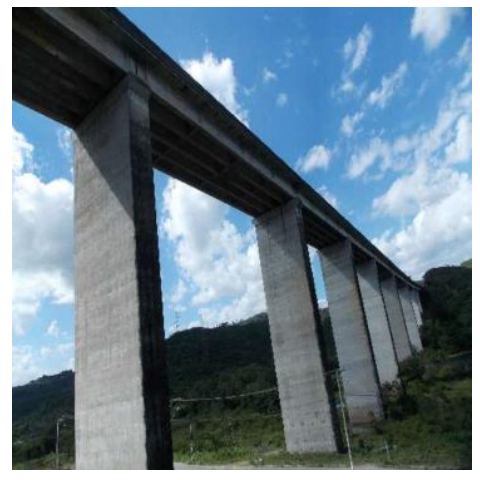

Figura 10- Imagem do relatório DNIT

A partir da análise das imagens da inspeção direta e inspeção com o drone, foi possível a identificação de certas manifestações patológicas, como por exemplo manchamentos de umidade nas cabeças dos pilares, sujidades de diferentes naturezas nos parâmentos de concreto, presença de vegetação aderida a estrutura (Figura 11), obstrução das juntas de dilatação pela camada de pavimento asfáltico (Figura 12), obstrução dos drenos, além de falha construtiva, como a presença de um dreno justamente no alinhamento da cabeça do pilar. O Quadro 2 mostra as anomalias encontradas a partir das imagens captadas pelo drone, bem como a sua existência em cada um dos elementos da estrutura.

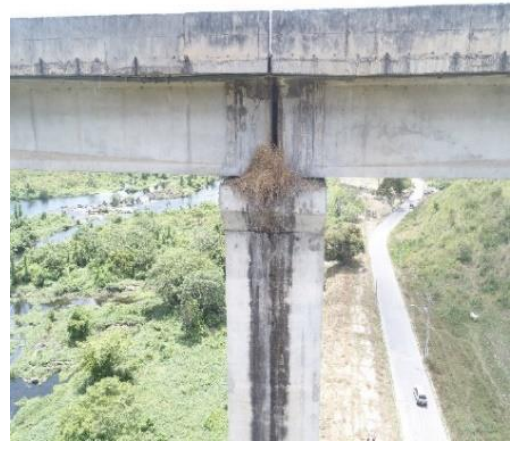

Figura 11- Pilar 3 presença de vegetação e manchas de umidade

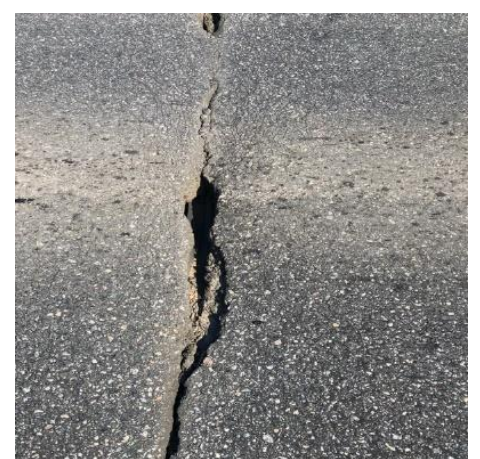

Figura 12 - Obstrução das juntas por material asfáltico 
Quadro 2 - Presença de manifestações patológicas, anomalias construtivas e falhas

\begin{tabular}{|l|c|c|c|c|c|}
\hline \multicolumn{7}{|c|}{ Manifestações patológicas - anomalias construtivas - falhas } \\
\hline & $\begin{array}{c}\text { Manchas de } \\
\text { umidade/mofo }\end{array}$ & Sujidade & Presença de vegetação & $\begin{array}{c}\text { Degradação de } \\
\text { material da junta }\end{array}$ & Obstrução \\
\hline Cabeça do pilar 1 & $\mathrm{x}$ & $\mathrm{x}$ & & & \\
\hline Cabeça do pilar 2 & $\mathrm{x}$ & $\mathrm{x}$ & & & \\
\hline Cabeça do pilar 3 & $\mathrm{x}$ & $\mathrm{x}$ & $\mathrm{x}$ & & \\
\hline Cabeça do pilar 4 & $\mathrm{x}$ & $\mathrm{x}$ & $\mathrm{x}$ & & \\
\hline Cabeça do pilar 5 & $\mathrm{x}$ & $\mathrm{x}$ & $\mathrm{x}$ & & \\
\hline Drenos & & & $\mathrm{x}$ & $\mathrm{x}$ & $\mathrm{x}$ \\
\hline Juntas de dilatação & & & & & \\
\hline
\end{tabular}

Mediante os dados coletados foi perceptível que a estrutura do concreto apresenta boas condições, pois não foram visualizadas fissuras relevantes, mas percebe-se uma leve lixiviação proveniente do concreto.

\section{Conclusões}

O drone se mostra um equipamento eficaz no que se refere a qualidade das imagens coletadas, permitindo a visualização de detalhes da ponte, observar a presença de manifestações patológicas como manchamentos de umidade e sujidade, presença de vegetação em locais inadequados e anomalias construtivas. Por consequência, o VANT apresenta grande potencial para auxiliar nas inspeções visuais diretas, normatizadas pelo DNIT, podendo influenciar na ampliação a frequência da execução das inspeções rotineiras, reduzir o número de pessoas em campo, o tempo para a execução das atividades e os custos referentes a uso de equipamentos e instalação de plataformas de acesso. Entretanto, é importante salientar que o equipamento mostrou limitações na visualização de alguns elementos, como por exemplo aparelhos de apoio, drenos e juntas, ratificando a imprescindibilidade de um trabalho paralelo entre a inspeção visual direta e o uso de VANT, além da necessidade de mais estudos a fim de reduzir as lacunas não preenchidas com novas soluções.

\section{Agradecimentos}

Ao Grupo de Tecnologia, Engenharia, Robótica e Física (G-TERF) da UFRB.

\section{Referências Bibliográficas}

BRASIL. ICA 100-40. Aeronaves Não Tripuladas e o Acesso ao Espaço Aéreo Brasileiro. Instrução do Comando da Aeronáutica. Departamento de Controle do Espaço Aéreo. Ministério da Defesa. Brasília, 2018.

DECEA AIC N 21/10: veículos aéreos não tripulados. Departamento de Controle do Espaço Aéreo, Rio de Janeiro, 2010.

DNIT, 2004. NORMA DNIT 010/2004 - PRO. Inspeções em pontes e viadutos de concreto armado e protendido - Procedimento. Instituto de Pesquisas Rodoviárias. Departamento Nacional de Infraestrutura de Transportes. Ministério dos Transportes. Brasil, 2017.

GIOVANNETTI, A. C. V. P. Avaliação do Estado de Conservação de Pontes - Estudo de Caso. Dissertação de mestrado. Universidade Federal de Santa Catarina. Centro Tecnológico. Florianópolis, 2014.

RAUBER, E.R et al. Análise Bibliográfica Sobre as Potencialidades da Aquisição de Imagens Multi e Hiperespectrais por VANTs no Auxílio à Inspeção de Obras de Arte Especiais. Revista Brasileira de Geomática. v. 6, n. 1, p. 44-61. Curitiba, 2018.

SANTOS, A. IBRACON (Instituto Brasileiro do Concreto) Concrete Show 2017. Disponível em $<$ https://docplayer.com.br/12185633-Previsao-de-vida-util-da-terceira-ponte-de-vitoria-es-o-estudo-dedeterminacao-da-vida-util-das-estruturas-de-concreto-da-terceira.html>. Acesso 08 de dezembro de 2019.

TCU. Departamento Nacional de Infraestrutura e Transporte. Monitoramento. Tribunal de Contas da União. Relatório. São Paulo, 2012. 